\title{
Zonation in migrating magnetococci
}

\author{
Michael J. Carlile ${ }^{1 *}$ and A. W. L. DudeneY ${ }^{2}$ \\ ${ }^{1}$ Department of Biology, Imperial College at Silwood Park, Ascot, Berks SL5 7PY, UK \\ ${ }^{2}$ Department of Mineral Resources Engineering, Imperial College of Science, Technology and Medicine, \\ London SW7 2BP, UK
}

(Received 23 November 1992; revised 4 May 1993; accepted 12 May 1993)

\begin{abstract}
Zone formation and movement of cells from mixed, natural colonies of magnetococci were studied. We concluded that (i) zoning resulted from hydrodynamic interaction between cells swimming in parallel as a result of magnetotaxis and (ii) magnetic interaction between cells had a role in determining the form and behaviour of zones. Our evidence is as follows. The formation of zones normal to the direction of movement during magnetotaxis requires that a component of the magnetic field be directed into a surface, resulting in cells being concentrated at the surface, facilitating cell interaction. The orientation of the surface with respect to gravity is irrelevant, excluding gravitation as a critical factor. Quasi-stable lateral associations between pairs of cells with similar speeds were observed, confirming a prediction that hydrodynamic interaction between cells could bring about such associations, and have a major role in the production of more extensive lateral associations including zones. Cells travelling much faster than a zone were observed to pass through it, although with some delay, suggesting that cells with speeds near that of the zone would be captured. In populations of slowly moving magnetococci, head-to-tail associations between cells were observed, indicating that at low swimming speeds magnetic instead of hydrodynamic interaction was dominant. When the direction of the magnetic field was reversed, the direction of zone movement was also reversed, and zones became narrower and more sharply defined for a few seconds. This was interpreted as a consequence of a magnetic effect of the mass of cells in a zone on cells at the zone edge. We also observed instability and gravitational fall of a dense layer of cells overlying cell-free fluid (Rayleigh-Taylor instability). This is well known with eukaryotic micro-organisms but has not been previously reported for bacteria.
\end{abstract}

\section{Introduction}

Magnetotactic bacteria (Blakemore, 1982; Frankel, 1984; Lins de Barros et al., 1990; Mann et al., 1990) are abundant in the top $1 \mathrm{~cm}$ of mud in most freshwater ponds but, being microaerophilic, are usually absent from the water above. Those from the northern hemisphere swim towards the North Pole. Northward swimming can also be demonstrated in artificial magnetic fields. If such a field is several times the intensity of that of the earth, then some species will form what have been termed zones (Carlile et al., 1987), bands (Spormann, 1987) or waves (Guell et al., 1988). A zone, the term that will be used here, consists of a long, narrow and dense mass of bacteria, with its long axis normal to the direction of the magnetic field. Zones migrate in the direction of the applied field at about the same speed as do individual cells. Migrating bacteria occur between zones, but their cell densities are much lower than those within zones. The basis of the effect is not well

* Author for correspondence. Tel. 0753 863174; fax 0344294339. understood, but Guell et al. (1988) suggest that hydrodynamic interaction between cells could account for the phenomenon. They calculate, using some simplifying assumptions, that two bacteria swimming parallel to each other with a separation of less than about 10 body radii will be attracted to each other. They then suggest ways in which such interaction might bring about zone formation. An assessment of the correctness of their theory requires more detailed observations on zone behaviour than those of Carlile et al. (1987) and Spormann (1987), and also on interaction between individual cells. Such observations, here reported, support the view of Guell et al. (1988) that hydrodynamic interaction is responsible for zone formation, but also suggest that magnetic interaction accounts for some features of zone form and behaviour.

\section{Methods}

Organisms and their maintenance. Few strains of magnetotactic bacteria have been grown in pure culture (Mann et al., 1990; Matsunaga et al., 1991). All but one of these are spirilla, which do not 
form zones. The exception is a vibrio (Bazylinski et al., 1988), but details of media and culture conditions for this organism were not given. The use of mixed, natural cultures was hence necessary. Mud and water were obtained from the pond in the Japanese Garden at the Imperial College Field Station at Silwood Park, and placed in plastic trays in the laboratory (Carlile et al., 1987). Except where otherwise stated, the work described here was carried out with magnetotactic bacteria from a single tray. These bacteria were cocci with a diameter of about $1.7 \mu \mathrm{m}$. Electron microscopy showed about 30 magnetite crystals per cell with maximum dimensions $95 \times 60 \times 60 \mathrm{~nm}$, a single polar flagellum and an extensive electron dense area, shown by electron probe analysis to be rich in calcium and phosphate. Cell speeds (and hence zone speeds) were lower than in the strains studied by Carlile $e t$ al. (1987) and Spormann (1987), with a mean of about $80 \mu \mathrm{m} \mathrm{s}^{-1}$ instead of the $120 \mu \mathrm{m} \mathrm{s}^{-1}$ observed previously. These cultures sometimes gave populations of magnetococci that were too sparse, had too poor motility to form zones, or failed to form zones at all. Usually, however, the populations obtained were dense, highly motile and zoned readily.

Provision of magnetic field. The magnetic field was obtained with a pair of $80 \mathrm{~cm}$ diameter Helmholtz coils with a coil separation of $44 \mathrm{~cm}$, each coil consisting of 1150 turns (about $3 \mathrm{~km}$ ) of $0.4 \mathrm{~mm}$ radius ceramic-sheathed copper wire. A toggle-switch enabled the field to be reversed or switched off. A Swift mineralogical microscope with a circular rotatable stage was mounted on a stand between the Helmholtz coils so that the coil axis passed through the centre of the stage and had a north-south orientation. With the coil axis horizontal, and a constant potential difference and current $(200 \mathrm{~V}$ and $0.33 \mathrm{~A})$ throughout, the horizontal component of the magnetic field was about $0.45 \mathrm{mT}$ at the centre of the microscope stage, and differed little whether the applied field was north or south. With the field in either direction there was a small downward component of the field, due to magnetic components of the microscope. When the coil axis was tilted $5^{\circ}$ to the north, the field had a downward inclination when the applied field was to the north, and an upward one when it was to the south. A Cooke, Troughton \& Sims microscope that could be tilted so that the stage was vertical was used for observing cell and zone movements in the vertical plane, with the axis of the Helmholtz coils either horizontal or vertical. The intensities of the horizontal and vertical components of the magnetic field and the calculated dip for the two microscopes and different coil configurations are given in Table 1. The usual experimental system, used except where otherwise indicated, was the Swift microscope with coil axis horizontal.

Concentrating and observing magnetotactic bacteria. Prior to experiments a drop of mud and pond water was placed on a microscope slide and a magnetic field applied. The quantity of cells accumulating at the north end of the drop was used to assess the amount of mud needed to provide adequate numbers of magnetotactic bacteria. Mud and accompanying water $(10 \mathrm{ml}$ portions) were transferred with a widemouthed Pasteur pipette to centrifuge tubes, mixed well, and centrifuged in a Sterispin 500 centrifuge. The speed was brought to 2000 r.p.m. $(670 \mathrm{~g})$ in a few seconds and the current then switched off; deceleration took about $40 \mathrm{~s}$. About $1 \mathrm{mg}$ catalase (Sigma bovine liver; 2600 units of enzyme per $\mathrm{mg}$ of solid) was added per $25 \mathrm{ml}$ of preparation; the catalase was used to protect the bacteria from damage by air. The supernatant was filtered through Whatman no. 1 filter paper. The resulting preparation of magnetotactic bacteria was free from debris and contained very few protozoa or larger organisms. The preparation was pipetted into a reservoir (Fig. 1), which was closed with a rubber bung which could be used as a piston to expel fluid into a microslide. When the observation chamber was a cuvette, the cuvette was filled directly with a Pasteur pipette. The system was checked to ensure that air bubbles were absent and so could not obstruct the migration of cells from reservoir to observation chamber. The reservoir

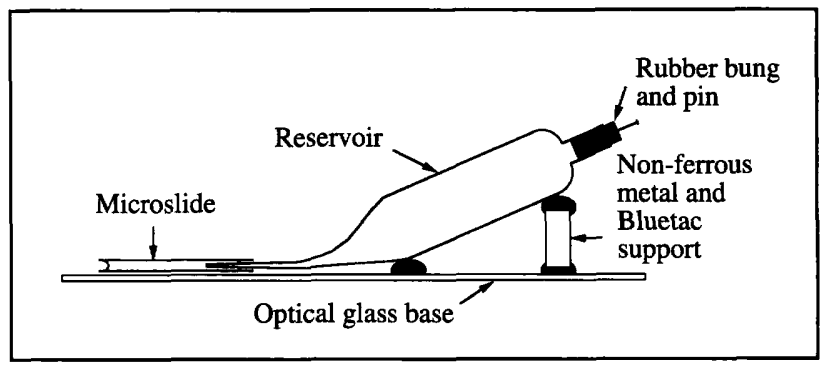

Fig. 1. Apparatus for concentrating and observing magnetotactic bacteria. The reservoir was made from a $25 \mathrm{ml}$ volumetric pipette. At the tapering end it is drawn out to form a capillary tube with a tip diameter of about $200 \mu \mathrm{m}$. This projects into a Camlab microslide, consisting of a flattened capillary tube, with internal dimensions $50 \times 4 \times 0.4 \mathrm{~mm}$ or $50 \times 3 \times 0.3 \mathrm{~mm}$. The vertical scale of the microslide and capillary tip is exaggerated for clarity. The apparatus was filled with the suspension from which magnetotactic bacteria were to be concentrated, and a magnetic field applied to bring about magnetotactic migration into the microslide. The reservoir shown may be replaced with one constructed from a Pasteur pipette if less concentration is needed. The microslide can also be replaced by a cuvette, with a reservoir of suitable design made from a $25 \mathrm{ml}$ volumetric pipette.

and observation chamber were mounted on an optically flat and clear strip of glass (Helma). This allowed manoeuvring and observation on the microscope stage. A magnetic field was then applied to bring about migration. Rapid oriented swimming of the magnetotactic bacteria occurred, so in a few minutes a stream of magnetococci entered the observation chamber. When the volumetric pipette with capillary tip was used, the ratio of bulb (20 mm diameter) and tip (about $0.2 \mathrm{~mm}$ diameter) cross-sections was such that an approximately 10000 -fold concentration of magnetococci had occurred by the time the cells had reached the capillary tip. The bacteria were observed at their point of entry into the observation chamber and in the course of their migration along it. The chamber was then detached from the reservoir and placed on a microscope slide. Further observations were then made, with the chamber placed so that migration occurred along its length or, alternatively, from one side to the other.

Videomicroscopy. A Panasonic CCD camera was mounted on the microscope, replacing the eyepiece, and events viewed with a Sony KX$14 \mathrm{CPl}$ monitor. Sequences of interest were recorded with a Panasonic VHS recorder. Cell paths, zone outlines and movements were determined by placing an acetate sheet over the monitor screen, replaying the videotape with frame-by-frame advance, and marking the acetate sheet at regular intervals. The scale of a stage micrometer was recorded at the beginning of each experiment to enable cell and zone speeds to be measured, the latter being determined with respect to a point on the rear edge of a zone, which was usually more sharply defined than the front edge. Using a $10 \times$ objective on the Swift microscope gave a $450 \times$ magnification on the monitor screen. This enabled individual cells to be followed for up to $500 \mu \mathrm{m}$ and their relationship to zones observed. The $3 \times$ objective enabled a field of $1.8 \times 1.3 \mathrm{~mm}$ to be viewed, so a sequence of zones could be observed simultaneously.

\section{Results}

\section{Zoning in relation to surfaces}

In typical experiments, zones were first observed moving along the fine capillary tube projecting from the reservoir 
Table 1. Magnitude and direction of the magnetic field provided by Helmholtz coils

The magnitude of the field in the horizontal (north-south) and vertical direction at the centre of the microscope stage was measured with a Bell model 615 gaussmeter in milliTesla $(\mathrm{mT})$, and the dip calculated.

\begin{tabular}{|c|c|c|c|c|c|c|}
\hline \multirow{2}{*}{$\begin{array}{l}\text { Experimental } \\
\text { system }\end{array}$} & \multicolumn{3}{|c|}{ Applied field to north } & \multicolumn{3}{|c|}{ Applied field to south } \\
\hline & Horizontal & Vertical & Dip & Horizontal* & Vertical $\dagger$ & Dip $\dagger$ \\
\hline \multicolumn{7}{|l|}{ Swift microscope } \\
\hline Coil axis horizontal & 0.458 & $0 \cdot 035$ & $4^{\circ}$ & -0.436 & 0.044 & $5 \cdot 5^{\circ}$ \\
\hline Coil axis tilted $5^{\circ} \mathrm{N}$ & 0.420 & $0 \cdot 115$ & $15^{\circ}$ & -0.422 & -0.038 & $-5^{\circ}$ \\
\hline \multicolumn{7}{|l|}{ Cooke microscope } \\
\hline Coil axis horizontal & 0.693 & 0.035 & $2 \cdot 5^{\circ}$ & -0.662 & 0.006 & $0.5^{\circ}$ \\
\hline Coil axis vertical $\ddagger$ & 0.012 & 0.729 & $89^{\circ}$ & 0.027 & -0.665 & $-87.5^{\circ}$ \\
\hline
\end{tabular}

* The minus sign indicates that field is to south.

† The minus sign indicates that field is upwards.

$\ddagger$ The coil has been tilted north through $90^{\circ}$, so here applied north is downwards and applied south upwards.

into the microslide (Fig. 1). On leaving the capillary tube, zones expanded and dispersed. With northwards migration, and the coil axis either horizontal or tilted, the resulting dip in the magnetic field (Table 1) soon brought cells to the bottom of the microslide where zoning was resumed. With the coil axis horizontal, reversal of the magnetic field resulted in reversal of the direction of zone movement. However, with tilted coils reversal gave the magnetic field an upward inclination (Table 1), and the zones left the bottom of the microslide and dispersed. Zonation on an upward facing horizontal surface - the bottom of a microslide or cuvette - was the basis for most of the work described by Carlile et al. (1987), Spormann (1987) and here. Zoning can, however, occur on surfaces having other orientations with respect to gravity, as indicated below.

Migration of cells from reservoir to microslide was carried out with tilted coils and the magnetic field to the south. As cells emerged from the capillary tube, the upward inclination of the field (Table 1) brought them to the upper surface of the microslide, where they formed zones. Zoning can hence occur on a downward-facing horizontal surface. A microslide with cells was then mounted on a Cooke microscope with the stage in the vertical plane, so that the flat surfaces of the microslide were also in the vertical plane. The microscope was then rotated so that the orientation of the vertical plane was at $10^{\circ}$ to the horizontal axis of the Helmholtz coils. Application of the magnetic field resulted in zoning on one face of the microslide, and reversal gave dispersal followed by zoning on the other face, so zoning can occur with cells moving horizontally on a vertical surface. With the Helmholtz coil axis and the Cooke microscope stage vertical (Table 1), upward or downward cell movement was obtained, depending on the direction of the magnetic field. Tilting the microscope stage $10^{\circ}$ out of the vertical plane caused zones to form on either the upper or lower face of the tilted microslide, dependent on the direction of cell movement. Zoning can hence be produced by cells that are moving upwards or downwards, as well as horizontally. The above experiments confirm that zoning will occur only at a surface, and with a component of the magnetic field directed into the surface, as already reported by Spormann (1987). They further indicate that the orientation of the surface and the direction of movement of the cells with respect to gravity is irrelevant.

\section{Zone form and cell movements}

Spormann (1987) illustrated zones shaped like arrow heads, with the tip pointing in the direction of movement. He acknowledged that this form was a consequence of zone formation in the bottom of a circular cross-section tube. A zone migrating on a flat surface has the form of a bar with its long axis normal to the direction of movement. Zones with a maximum width of $25 \mu \mathrm{m}$ or less typically have both the front and rear edges clearly defined but slightly irregular with minor variations in outline as migration proceeds. Wider zones containing a large number of cells show a difference between their front and rear, this difference being perceptible in some zones with a maximum width of $25-30 \mu \mathrm{m}$ and becoming more obvious in wider zones. The rear edge in this type of zone is only a short distance behind the region of maximum cell density and is sharply defined. Cell numbers gradually decrease in front of the region of maximum cell density, so the front edge of a wide zone is ill-defined. Therefore the width of a wide zone cannot be measured very precisely. Wide zones usually taper gradually at their two ends to a point, so that the narrow part of a wide zone resembles a narrow zone, with no marked differences between front and rear. A single band of cells that has recently left the side of a microslide, and 
(a)

(b)
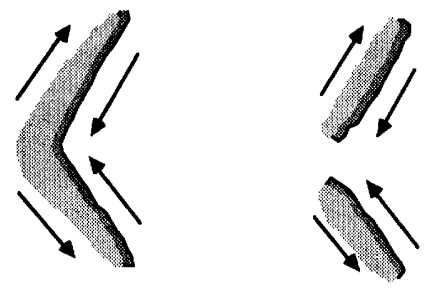

$(d)$

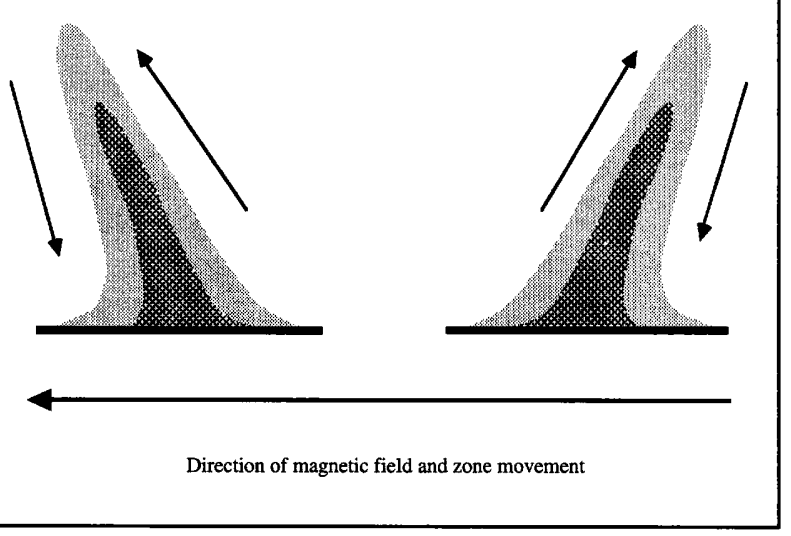

Fig. 2. Diagrammatic representation of migrating zones. The relative cell density is indicated by stippling, and cell movement in relation to zones by arrows with unbroken shafts. (a) Arrow-shaped zone as illustrated by Spormann (1987), with cell movement outward at the front of the zone and inward at the rear. (b) A bar-shaped zone that developed with a normal orientation with respect to the direction of the magnetic field, but which has been rotated clockwise (above) and anticlockwise (below) to oblique positions. The resulting directions of cell movement provide an explanation for those observed with arrowshaped zones. (c) Postulated actual cell movement at the front, within, and at the rear of an oblique zone, with the direction of the magnetic field (broken line) included for clarity. Such movement, in a zone that is advancing, would give the apparent cell movement observed. (d) A large zone, viewed from the side, having a forward inclination in the direction of cell movement. The cell movements in the vertical plane, upward at the rear of the zone and downward at the front, simulate a wheel-like rolling of the zone. (e) A similar zone, with a backward inclination, and vertical cell movement and apparent zone rolling in the direction opposite to that in $(d)$.

has not yet broken into zones, shows the same differences between front and rear as wide zones.

Spormann (1987) reported lateral cell movements in arrow-shaped zones, outwards at the front and inwards at the rear (Fig. 2a). We have not seen such movements in zones having their long axis normal to the direction of zone migration. Lateral cell movement is obvious, however, in zones that have been placed with their long axes diagonal to the direction of the magnetic field and of zone movement (Fig. $2 b$ ). Such rotation does not change the speed with which the zone is advancing parallel to the direction of the magnetic field. However, cells at the front edge of such a zone appear to be moving backward parallel to the front edge, and those at the rear edge forward parallel to that edge. The apparent backward movement at the front edge of an oblique zone is an illusion, due to the forward movement of the zone as a whole. A slight deflection of cell movement from the direction parallel to the magnetic field (Fig. $2 c$ ) is sufficient to account for the illusion. The cell movements at the front and rear of oblique zones are consistent with the observation by Spormann (1987) of outward movement at the front and inward movement at the rear of arrow-shaped zones, as is seen by comparing Fig. 2(a) and Fig. 2(b).

Spormann (1987) stated that the cell mass in a zone rolled over the capillary surface as it progressed, although he was unable to determine whether the mass rolled as a wheel or in the opposite direction. We have not observed any indication of such rolling in zones on the flat surface of a cuvette or microslide in the course of normal microscope observations from above. Experiments were hence carried out with the stage of a Cooke microscope in the vertical plane, coils horizontal (Table 1), and a microslide with its long axis horizontal and its flat surfaces parallel to the microscope stage. This gave a side view of zones moving along the bottom of the microslide. Cell movements, other than those in an approximately horizontal direction and parallel to the magnetic field, were not seen in small zones. Cell movements in the vertical plane were seen in the outer part of very large zones having an opaque core with a width and height greater than $100 \mu \mathrm{m}$. Such movements were most marked and consistent in direction in zones that were tilted with respect to the direction of zone movement. In these (Fig. $2 d, e$ ) the apparent direction of cell movement was as expected from observations of zones obliquely aligned in the horizontal plane (Fig. $2 b$ ). The cell movements could be construed as a wheel-like rolling in zones that were tilted forward, and as rolling in the opposite direction in backwardly tilted zones. Marked cell movements in the vertical plane hence appear to result from the deflection of cells by a dense cell mass rather than being due to any consistent pattern of rolling by the mass.

With the Helmholtz coil axis horizontal, a reversal of the magnetic field resulted in migrating zones moving in the opposite direction and at the same speed, as would be expected. However, shortly after the field is reversed, zones were narrower and more sharply defined than at other times. The movement of zones immediately after field reversal was therefore studied in more detail (Table 2). During the first second after field reversal the new zone rear moved faster than the normal speed of the 
Table 2. Movement and width of a zone following reversal of the magnetic field

\begin{tabular}{|c|c|c|c|}
\hline \multirow{2}{*}{$\begin{array}{c}\text { Time from reversal* } \\
\text { (s) }\end{array}$} & \multicolumn{2}{|c|}{$\begin{array}{l}\text { Distance moved in the previous second } \dagger \\
\qquad(\mu \mathrm{m})\end{array}$} & \multirow{2}{*}{$\begin{array}{l}\text { Zone width } \\
(\mu \mathrm{m})\end{array}$} \\
\hline & New rear & New front & \\
\hline 0 & - & - & 59 \\
\hline 1 & 78 & 48 & 29 \\
\hline 2 & 61 & 61 & 29 \\
\hline 3 & 58 & 65 & 36 \\
\hline 4 & 55 & 65 & 46 \\
\hline
\end{tabular}

* The frame of the videorecording in which the magnetic field was reversed showed colour differences as compared with other frames, an effect normal in field reversal.

† The magnification employed and the irregularity of the zone boundaries was such the values are reliable to about $\pm 2 \mu \mathrm{m}$. The zone speed as determined at the zone rear, 3-5 s after a further reversal, was $57 \mu \mathrm{m} \mathrm{s}^{-1}$.

zone, and became sharply defined. The speed of the new zone front, however, was slower than the normal zone speed. As a result, the zone became narrower. During the following $2-3 \mathrm{~s}$ the speed of the new zone rear diminished to that characteristic of the zone. Meanwhile, the new zone front increased in speed to a value greater than normal and at the same time ceased to be sharply defined, developing the normal appearance of a zone front. With the zone front moving faster than the zone rear, band width increased once more. At the magnification employed, it was not possible to follow zones for more than 4-5 s after field reversal, but observations with a lower magnification and larger field indicated that the normal zone width was soon reached and maintained. The speed of the zone front must therefore soon diminish to that of the rear. Transient narrowing as a result of magnetic field reversal was also seen in narrow zones, in which differences between front and rear were not obvious. Repeated reversals of the magnetic field with an interval of 1-2 s led to zones becoming very narrow, and could induce sharply defined zones in cell populations in which the tendency to zone formation was slight.

\section{Zone formation}

Zonation can develop in a migrating mass of cells (Carlile et al., 1987; Spormann, 1987). The effect can be produced clearly and repeatedly, for example, in a microslide between coils tilted by $5^{\circ}$ (Table 1 ). Cells were concentrated at the south side of the microslide, and when the magnetic field was reversed cells left the edge of the microslide as a single band having, like a zone, a sharply defined rear and a less clearly defined front. Unlike a zone, however, the band was unstable; the front moved ever further from the rear, and the whole cell mass became less dense, to give a swarm rather than a band. After $20 \mathrm{~s}$, zonation occurred within the swarm, with zones just being perceptible close to the sparse front of the swarm and more prominent where cell density was greater. The fastest zones were at the front and the slowest at the rear. At $25 \mathrm{~s}$ the three most prominent zones, those in the middle of the swarm, were about $100 \mu \mathrm{m}$ apart and had speeds of 83,75 and $69 \mu \mathrm{m} \mathrm{s}^{-1}$. The microslide was then rotated through $90^{\circ}$, so that the bands of cells became streams moving parallel to each other. Within $2 \mathrm{~s}$ of completing the rotation, the streams had broken into well-defined zones. The speeds of three successive zones in the stream that was derived from the $75 \mu \mathrm{m} \mathrm{s}^{-1}$ band were determined. All had speeds of $76 \mu \mathrm{m} \mathrm{s}^{-1}$, identical within the limits of observational error $\left( \pm 2 \mu \mathrm{m} \mathrm{s}^{-1}\right)$ with that of the zone from which they had been derived. Hence, cells that differed greatly in speed could not be retained within a single band or zone, although a population of cells with similar speeds could, under appropriate conditions, give rise to numerous zones of the same speed.

\section{The behaviour of single cells, in relation to other cells} and to zones

Cells from a reservoir continued to enter a microslide for a long time after zones became established. Some of these cells were travelling much faster than the zones. The interaction of such cells with zones was observed in areas where cell numbers between zones were sufficiently low for individual cells to be followed for several seconds. These areas occurred towards zone ends, mainly where zone width was $25 \mu \mathrm{m}$ or less. Fast cells were observed to catch up with zones and to pass through them without obvious delay. However, since the route taken by cells 
passing through zones was irregular compared with their otherwise nearly smooth path, it would seem that a slight delay must have occurred.

The paths of 12 selected cells that traversed zones were studied further with frame-by-frame advance of the videotape, the positions of the cells and of the corresponding rear edges of zones being recorded at regular intervals. Zone speeds ranged from 58 to $91 \mu \mathrm{m} \mathrm{s}^{-1}$. Ten of the cells selected had speeds ranging from 16 to $51 \%$ faster than the corresponding zones, and entered the zones as soon as they reached the zone edge. One cell with a speed $15 \%$ greater than that of the corresponding zone was slightly deflected prior to entering the zone. A further cell, with a speed only $7 \%$ greater than the zone it approached, was deflected for over $12 \mu \mathrm{m}$ along the rear edge of the zone and failed to penetrate the zone for over $0.2 \mathrm{~s}$. Since during this period the cell and the rear edge of the zone continued to advance, this represents a delay in progress of about $0 \cdot 1 \mathrm{~s}$.

The above cells were selected as exceptionally fast, and hence not typical of cells near zones. Further cells were therefore studied, the only criteria in their selection being that they were sufficiently isolated to be followed without confusion with other cells, and that they were in the same field as a zone. They were selected with the videoplayer on pause, to avoid unconscious bias towards fast or slow cells. Some cells were non-motile, but 26 cells were followed for $1 \mathrm{~s}$ or more, their positions being recorded at regular intervals and their speeds determined. Only one of the cells disappeared into a zone-moving at $49 \mu \mathrm{m} \mathrm{s}^{-1}$ it was captured by a zone moving at $86 \mu \mathrm{m} \mathrm{s}^{-1}$. The distribution of cell speeds approximated to a normal distribution, with a mean cell speed of $82 \mu \mathrm{m} \mathrm{s}^{-1}$ and a standard deviation of $20 \mu \mathrm{m} \mathrm{s}^{-1}$. The mean cell speed was hence similar to the mean $\left(84 \mu \mathrm{m} \mathrm{s}^{-1}\right)$ of that of the adjacent zones, which had speeds of $79,81,86$ and $91 \mu \mathrm{m} \mathrm{s}^{-1}$.

Pairs of cells that remained close together in a quasistable relationship were sometimes observed. An examination was made of the paths of seven such pairs of cells moving in a northward direction with the axis of the Helmholtz coils horizontal (two pairs) or tilted by $5^{\circ}$ (five pairs). The location of the zone pairs, within $100 \mu \mathrm{m}$ of zone ends, and their speeds, similar to those of the adjacent zones, suggested that the cell pairs may have escaped from zone ends. The positions of the members of each pair were recorded at $0.2 \mathrm{~s}$ intervals, pairs being followed for times ranging between 1.2 and $3 \cdot 2 \mathrm{~s}$, giving a total of 102 readings. The distance between members of a pair of cells fluctuated. The mean distance between cell centres was $4.8 \mu \mathrm{m}$ and hence the mean cell separation (i.e. the distance between cell surfaces) was $3 \cdot 1 \mu \mathrm{m}$, allowing for a mean cell diameter of $1.7 \mu \mathrm{m}$. The distribution of cell separation distances was skewed (Fig.
3). The distances recorded, however, are those of the projection of cells on a plane normal to the axis between the observer and the cells. When cells were close to each other, one was usually a little out of focus, so the real distance between close cells was underestimated. This suggested that the distribution of real cell distances was more markedly skewed, with a sharply defined minimal distance a little less than the mean. The angle of the axis between cell centres and the direction of the magnetic field in the horizontal plane was also determined for each cell pair position (Fig. 4), giving a skewed distribution (mean $53^{\circ}$ ) with no cells head-to-tail $\left(0-20^{\circ}\right)$ but also few precisely side-by-side $\left(81-90^{\circ}\right)$. As a pair of cells progressed, fluctuations in the angle occurred, but with the same cell remaining ahead for much and sometimes the entire period that the cell was followed. When the order of the two cells changed, this was usually the result of a close encounter with another cell or cell pair.

Although in the above studies head-to-tail configurations were not observed with swimming pairs of bacteria, late in experiments cells sometimes formed needle-like structures with their long axes parallel to the magnetic field. The width of these needles indicated that they consisted of a single line or occasionally two or more parallel lines of cells. The growth of needles occurred from a dense layer of cells that had accumulated in the curved corners at the end of cuvettes following magnetotactic migration. Cells migrating through a cuvette towards the layer did not attach themselves to the end of needles even though needle extension was continuing. Needle growth must hence occur by the addition of cells within the dense layer, perhaps at the base. Reversal of the magnetic field caused needles to leave the cuvette edge and migrate parallel to the magnetic field. Presumably a $180^{\circ}$ rotation of the cells in the needles occurred. The rate of migration of needles was much slower than that of cells and was inversely proportional to needle length. For example, a $6 \mu \mathrm{m}$ needle was observed to move at $9 \mu \mathrm{m} \mathrm{s}^{-1}$ and an $18 \mu \mathrm{m}$ needle at $3 \mu \mathrm{m} \mathrm{s}^{-1}$. Migration of long needles $(25-100 \mu \mathrm{m})$ was too slow to distinguish from movements caused by convection currents in the cuvette. The inverse relationship between needle length and migration speed suggested that the propulsive force was similar for long and short needles, as would occur if only the flagella in the terminal cell were effective in propulsion. An experiment was carried out with the Swift microscope stage in the vertical plane and a pair of small Helmholtz coils (diameter $20 \mathrm{~cm}$ ) with axis horizontal in addition to the usual pair with axis vertical. This allowed the magnetic field to be vertical (large coils only), horizontal (small coils only) or with a $60^{\circ}$ dip (both pairs of coils), and the field direction to be changed to varying extents ranging from $30-180^{\circ}$. The behaviour of needles under 


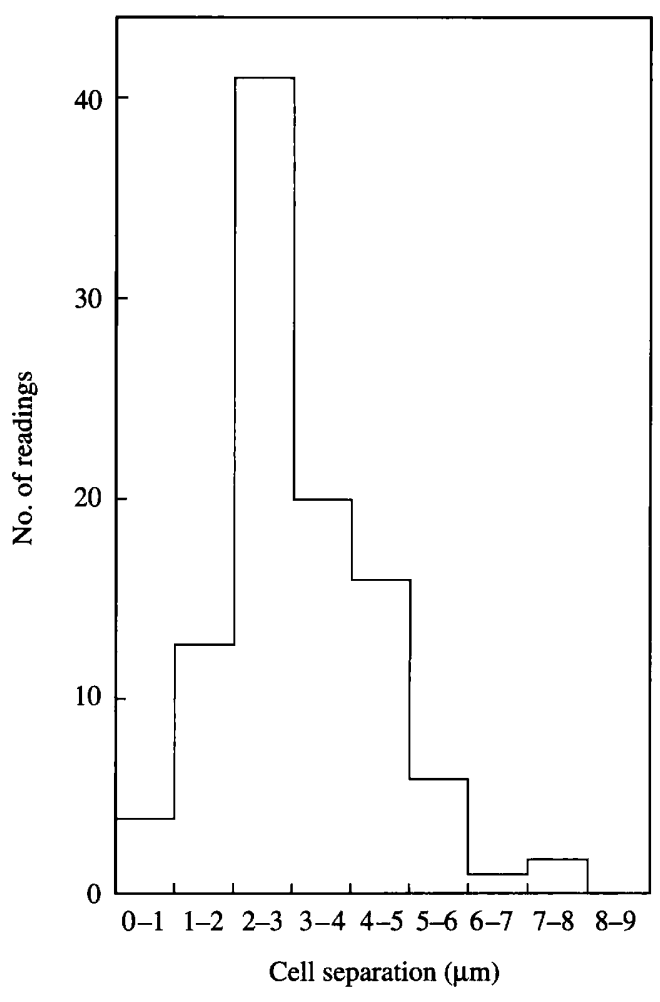

Fig. 3

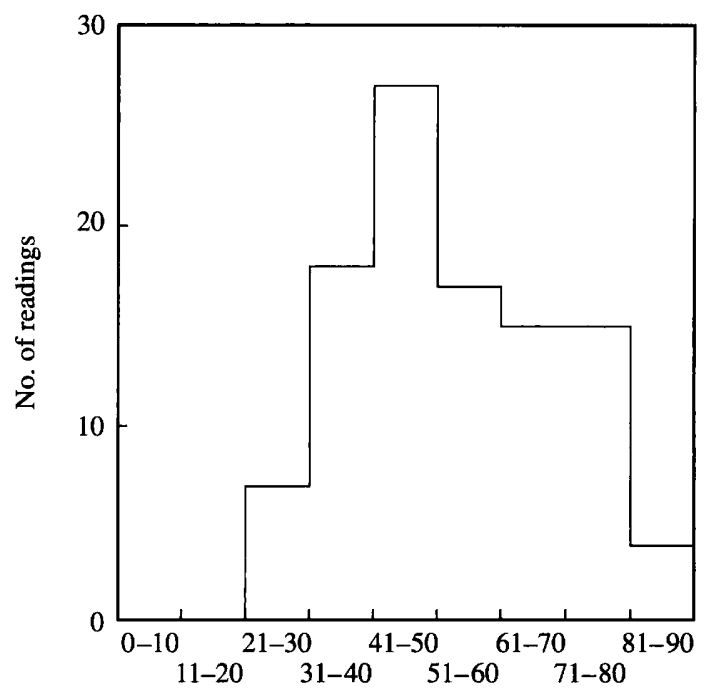

Angle $\left({ }^{\circ}\right)$ between cell pair axis and magnetic field direction

Fig. 4

Fig. 3. The distances separating members of cell pairs. The distances between cell pairs were determined (accuracy about $\pm 0.5 \mu \mathrm{m}$ ) and the mean cell diameter $(1 \cdot 7 \mu \mathrm{m})$ was deducted.

Fig. 4. Angle between the axis linking the centre of cell pairs and the direction of the magnetic field in the horizontal plane.

$25 \mu \mathrm{m}$ resembled that of compass needles, attaining their new alignment within a second. Larger needles were liable to break. A $60^{\circ}$ field rotation resulted in a single break in a $38 \mu \mathrm{m}$ needle and seven breaks in an $87 \mu \mathrm{m}$ needle. Breaks late in a turn were usually followed by rejoining, since broken ends were close together. Early breaks resulted in ends that were far apart, and hence no rejoining, or sometimes joining with ends of other needles. Frame-by-frame advance of the videotape showed curvature of needles during rotation, with needles having an S-configuration in the middle of a $180^{\circ}$ turn. Rapidly repeated field reversals resulted in the disruption of needles to release faster, smaller needles and single motile cells which were slow (about $20 \mu \mathrm{m} \mathrm{s}^{-1}$ ).

A drop of mud and water from a tray other than that usually employed was placed on a microscope slide and a magnetic field applied. Two different types of magnetococci were present. The more abundant species appeared to be that used for the experiments already described. The other species was smaller, diameter about $1 \mu \mathrm{m}$, and slower, moving at about $20 \mu \mathrm{m} \mathrm{s}^{-1}$. This is, for magnetotactic bacteria, a very low speed, so it is possible that the species is highly sensitivity to oxygen, and suffers impaired motility when exposed to air. With this species cells were often seen swimming in a head-to-tail configuration. Pairs were most frequent, but three, four or even larger numbers of cells swimming in line were not uncommon. The distance between cells was commonly $1.5 \mu \mathrm{m}$ or less, with a tendency to diminish with time, until cells may well have been in contact. The speeds of single cells, pairs of cells and chains were similar, suggesting that all the cells were active in propulsion. Head-to-tail configurations have thus been observed in abnormally slow magnetococci, as well as in the needles formed in dense layers of normal cells.

\section{Effect of gravity on dense cell suspensions}

The Cooke microscope was tilted to bring the stage into the vertical plane, and a cuvette containing a suspension of magnetococci was mounted horizontally. With the axis of the Helmholtz coils vertical, an upwardly directed magnetic field was applied. The cells swam upward and accumulated as an optically dense, nearly opaque, layer at the top of the cuvette. On reversing the magnetic field, the cells began to descend as a band, the leading edge 
moving at a constant speed, within the limits expected for swimming cells. Within a few seconds, however, a more rapid descent in one part of the band became apparent, and the band becomed curved. Streaming of cells to the more rapidly descending part of the band occurred, and it soon became drop-shaped with a tail. The drop of dense bacteria descended with constant acceleration until a terminal velocity of about $700 \mu \mathrm{m} \mathrm{s}^{-1}$ was approached. The production of a dense layer of cells above fluid with few cells, through an upwardly directed taxis (positive phototaxis or negative geotaxis), and the subsequent descent of cell masses as a result of Rayleigh-Taylor instability, is well known in eukaryotic micro-organisms (Plesset \& Winet, 1974; Plesset et al., 1976), but apparently has not been observed before with bacteria. The present observations establish that a dense population of magnetococci can be affected by gravity. It is possible that gravity may influence the behaviour of the massive zones in which apparent rolling occurs.

\section{Discussion}

The theoretical study by Guell et al. (1988) indicated that if two bacteria are swimming near to each other, they interact hydrodynamically. If they are swimming sideby-side, the interaction is attractive, if head-to-tail, repulsive. A pair of magnetococci will also interact magnetically, but with head-to-tail attraction and lateral repulsion. If the cells are very close together, up to a separation of a little over one cell radius, then according to equation (14) of Guell et al. (1988) magnetic forces will be dominant. At greater distances hydrodynamic forces are dominant, with their strength diminishing with distance, until at 10 cell radii they are little larger than the Brownian force - equation (15) of Guell et al. (1988). The location of regions of attraction and repulsion experienced by one magnetococcus swimming in the vicinity of another is indicated in Fig. 5 . It will be seen that a quasi-stable relationship is likely with a pair of cells swimming side-by-side; if they come closer together they will be repelled, and if they move further apart they will be attracted. A stable head-to-tail relationship between strongly swimming cells will, however, be unlikely, since hydrodynamic repulsion could prevent the cells getting close enough for magnetic attraction to dominate. With less vigorous cells, and hence reduced hydrodynamic interaction, close approach might occur, but then continuing attraction (Fig. 5) might lead to actual contact.

Our observations are in general agreement with the theoretical treatment of Guell et al. (1988). Pairs of cells were seen to swim in side-by-side configurations for as long as they could be followed, and head-to-tail configurations were not seen with strongly swimming cell pairs. The maximum distance observed between cells maintaining a stable lateral relationship was about $8 \mu \mathrm{m}$ (Fig. 3) or 9 cell radii, in conformity with the predicted outer limit of 10 cell radii for appreciable hydrodynamic attraction. However, the mode of the distances between cell pairs, which should approximately correspond to the distance at which magnetic and hydrodynamic forces are equal and opposite, was 2-3 $\mu \mathrm{m}$ (Fig. 3) or 2.4-3.5 cell radii, 2-3 times greater than that which would be expected from equation (14) of Guell et al. (1988). Their treatment of the hydrodynamic forces between the cells is based on the Stokes' formula for the drag on a sphere moving through a fluid, and involves various simplifying assumptions. The Stokes' formula is unsatisfactory for distances similar to or not much greater than the sphere

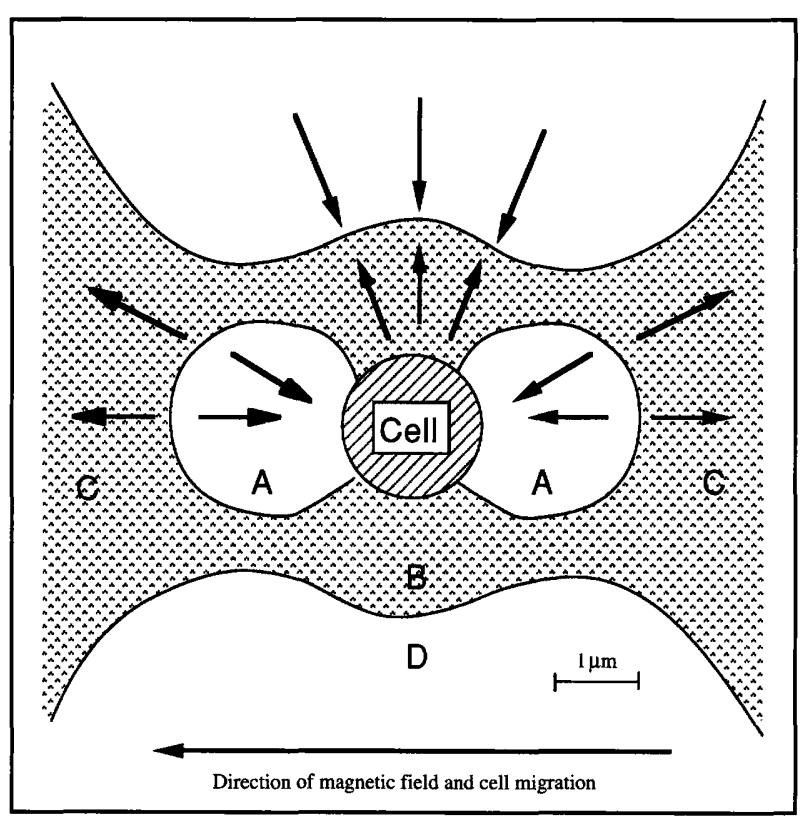

Fig. 5. Representation of the spatial distribution of the forces between a magnetococcus (diameter $1.7 \mu \mathrm{m}$ ) swimming to the left (labelled 'cell') on a nearby second magnetococcus (not shown), based on the theoretical treatment by Guell et al. (1988) and present observations. If the second cell is close to the front or rear of the first, there will be mutual magnetic attraction (A). However, if the second cell is close to the side of the first, there will be mutual magnetic repulsion (B). At a greater distance there will be head-to-tail hydrodynamic repulsion (C) and lateral attraction (D). Because of the region of mutual repulsion entirely surrounding a cell (stippled area), a second cell will only enter a area of mutual magnetic attraction (A) under exceptional circumstances. With side-to-side cells, however, the direction of the forces experienced (arrows) is such that a quasi-stable situation results, with the forces tending to direct the second cell (not shown) to the boundary between the zones of attraction (D) and repulsion (B). The diagram is based on the assumption that hydrodynamic forces dominate beyond a distance of about 3 cell radii from the cell surface: for clarity the direction of the dominant forces is omitted in the lower part of the diagram. 
radius (Landau \& Lifshitz, 1987). Hence, although the Guell et al. (1988) treatment provides valid qualitative predictions, it cannot yield a precise value for the distance at which hydrodynamic and magnetic forces are equal.

We found a low frequency of cell pairs with precisely side-by-side associations (Fig. 4), the most likely configuration on the basis of hydrodynamic interaction alone. This suggests that even at high swimming speeds, dominance of hydrodynamic over magnetic forces is not total. At low swimming speeds (e.g. $20 \mu \mathrm{m} \mathrm{s}^{-1}$ ) magnetic forces are dominant, as shown by head-to-tail associations and needles. This may explain why healthy magnetotactic bacteria have high swimming speeds (e.g. $80-120 \mu \mathrm{m} \mathrm{s}^{-1}$ ) when compared with other bacteria, for example the $18 \mu \mathrm{m} \mathrm{s}^{-1}$ mean speed for Salmonella typhimurium (Poole et al., 1988); at low swimming speeds immobilization could occur.

The conditions needed for zone formation by magnetococci are a magnetic field with an intensity a little greater than that of the geomagnetic field, a component of the field directed into a surface, a high cell density and healthy, highly motile cells (Carlile et al., 1987; Spormann, 1987). Although the Earth's magnetic field is of an adequate intensity to produce approximately northward swimming, a higher intensity field will result in slighter deviations from a precisely northward path (Kalmijn, 1981). The field component directed into a surface will result in all the cells moving in parallel along that surface, and high cell densities will ensure that cells are near each other. Together these factors will greatly enhance the probability of interaction between cells and, when vigorously swimming, of lateral hydrodynamic attraction.

Guell et al. (1988) proposed that hydrodynamic interaction is the basis for zone formation and that the magnetic field acts by promoting parallel swimming and hence hydrodynamic interaction. The formation of waves or zones occurs in populations of ram or bull spermatozoa - for an illustration see Rothschild (1949) - where it is used as an indication that the spermatozoa are healthy and highly motile and thus suitable for use in artificial insemination (Salisbury et al., 1978). The waves in spermatozoa further resemble the zones of magnetococci in that, under favourable conditions, zones can form in about $1 \mathrm{~s}$ (Glover, 1968). The occurrence of these waves in spermatozoa, where there is good evidence for hydrodynamic interaction and lateral attraction between cells (Reynolds \& Rothschild, 1963; Rothschild, 1963) and none for magnetic sensitivity, supports the view that zone formation is primarily a hydrodynamic phenomenon.

Since stable lateral associations between pairs of magnetococci occur readily, it is easy to envisage that the forces involved in pair formation are able to produce the thin lateral strings of cells that Spormann (1987) illustrated (his Fig. 1b). A well-developed zone, however, is many cells in width. Although cells moving much faster than a zone will pass through it, some delay occurs, presumably partly through hydrodynamic attraction of laterally placed cells and partly through physical obstruction. It is hence reasonable to suppose that cells that differ little in speed from that of the zone will be delayed indefinitely, thus leading to an increase in zone width. It was also observed that cells reaching the rear of a zone could fail to penetrate immediately and could move along the rear edge. This effect could result in deflected cells filling any 'bays' at the zone rear and thus helping to maintain a smooth rear edge. Wide zones of magnetococci differ from spermatozoa in having a marked difference between front and rear, cell density decreasing rapidly behind the region of maximum cell density, but slowly in front of it. This could be due to magnetic attraction of cells by the region of high cell density. Such attraction would increase the speed of cells behind the zone, bringing them close to the region of maximum density. With the cells in front, a slight reduction in cell speed would be likely, retaining cells that would otherwise have escaped in the vicinity of the zone. Such effects are suggested by the speeds of the zone edges recorded after zone reversal; the new zone rear initially moves very rapidly and the new zone front very slowly (Table 2). Thus, although zone formation is primarily a mechanical phenomenon, involving lateral hydrodynamic attraction, physical obstruction and hence perhaps 'queueing', it seems likely that the form of the zone - sharp rear and diffuse front - is influenced by the magnetic properties of the cells.

Magnetotactic bacteria have an unexploited potential for the study of bacterial motility. Cells can be induced to travel in nearly straight paths and, by means of magnetic field reversal, prolonged observations can be made on single cells. Pairs of cells derived from zones and swimming on parallel paths in close proximity provide opportunities for the study of hydrodynamic and other forms of interaction between cells. Zoning itself is not relevant to bacterial behaviour in nature, as the magnetic fields needed for zoning are of greater intensity than the geomagnetic field. The development of a fully quantitative theory of zoning, however, would provide a good test of our understanding of the various forms of physical interaction that can occur between motile cells.

We wish to thank Graham Briers for electron microscopy, John Sullivan for the construction of the Helmholtz coils, Bill Harman for help with video equipment, Dr Michael Holwill (King's College, London), Dr Alun Roberts (South Bank University), Professor Pavel Bedrikovetski and Alexander Shapiro (Moscow State Oil and Gas 
Institute) for hydrodynamic advice and Heerema Engineering Services (UK) Ltd for financial support.

\section{References}

Bazylinski, D. A., Frankel, R. B. \& Jannasch, H. W. (1988). Anaerobic magnetite production by a marine, magnetotactic bacterium. Nature, London 334, 518-519.

Blakemore, R. P. (1982). Magnetotactic bacteria. Annual Review of Microbiology 36, 217-238.

Carlile, M. J., Dudeney, A. W. L., Hebenstreit, B. K. \& Heerema, R. H. (1987). Zoned migration in magnetotactic bacteria. Journal of Magnetism and Magnetic Materials 67, 291-294.

Frankel, R. B. (1984). Magnetic guidance of organisms. Annual Review of Biophysics and Bioengineering 13, 85-103.

GLOVER, F. A. (1968). Physical method of measuring the motility of bull spermatozoa. Nature, London 219, 1263-1264.

Guell, D. C., Brenner, H., Frankel, R. B. \& Hartmann, H. (1988). Hydrodynamic forces and band formation in swimming magnetotactic bacteria. Journal of Theoretical Biology 135, 525-542.

KalmiJn, A. J. (1981). Biophysics of geomagnetic field detection. IEEE Transactions on Magnetics Mag-17, 1113-1124.

LANDAU, L. D. \& Lifshitz, E. M. (1987). Fluid Mechanics, 2nd edn. Oxford: Pergamon Press.

Lins de Barros, H. G. P., Esquivel, D. M. S. \& Farina, M. (1990). Magnetotaxis. Science Progress 74, 347-359.
Mann, S., Sparks, N. H. C. \& Board, R. G. (1990). Magnetotactic bacteria: microbiology, biomineralization, paleomagnetism and biotechnology. Advances in Microbial Physiology 31, 125-181.

Matsunaga, T., SaKaguchi, T. \& TADOKORO, F. (1991). Magnitite formation by a magnetic bacterium capable of growing aerobically. Applied Microbiology and Biotechnology 35, 651-655.

Plesset, M.S. \& WINET, H. (1974). Bioconvection patterns in swimming microorganism cultures as an example of the Rayleigh-Taylor instability. Nature, London 248, 441-443.

Plesset, M. S., Whipple, C. G. \& Winet, H. (1976). Rayleigh-Taylor instability of surface layers as the mechanism for bioconvection in cell cultures. Journal of Theoretical Biology 59, 331-351.

Poole, P. S., Sinclair, D. R. \& ARmitage, J. P. (1988). Real time computer tracking of free-swimming and tethered rotating cells. Analytical Biochemistry 175, 52-58.

ReYNolds, A. J. \& RothsCHILD, LORD (1963). The stirring of the medium by bull spermatozoa. Proceedings of the Royal Society B147, 461-472.

ROTHSCHILD, LORD (1949). Measurement of sperm activity before artificial insemination. Nature, London 163, 358-359.

ROTHSCHILD, LORD (1963). Non-random distribution of bull spermatozoa in a drop of sperm suspension. Nature, London 198, 1221-1222.

Salisbury, G. W., van Denmark N. L. \& Lodge, J. R. (1978). Physiology of Reproduction and Artificial Insemination in Cattle, 2nd edn. San Francisco: W. H. Freeman.

SPORMANN, A.M. (1987). Unusual swimming behavior of a magnetotactic bacterium. FEMS Microbiology Ecology 45, 37-45. 